\title{
Narrativa y crimen en el periodo colonial: notas para una discusión ${ }^{*}$
}

\author{
Dr. Luis Hachim Lara**
}

\begin{abstract}
Resumen
La reflexión sobre la narrativa hispanoamericana no se puede circunscribir sólo al siglo XIX, puesto que los estudios del periodo colonial han certificado Crónicas, Relaciones y diversos relatos, ya en la segunda mitad del siglo XVI, no sólo escritos por europeos o mestizos, sino también textos de letrados indígenas que incorporaron una radicalización de la denuncia y una interpelación al sujeto dominador. Este trabajo propone una aproximación crítica a un conjunto de textos que ya en el periodo colonial denunciaron narrativamente el crimen, a través de diversas formas del enunciado, configurando una de las constantes del pensamiento crítico y literario. Estas narrativas, junto con profundizar la memoria, asumieron la justicia de nombrar y el acto que expuso desde el lugar del otro, la historia o las historias de esos hechos en América.
\end{abstract}

Palabras clave: Pensamiento crítico y literario latinoamericano, estudios coloniales, Ilustración Católica Hispanoamericana, historias naturales, estudios narrativos.

\section{Colonial Period Narrative and Crime: Notes for a discussion}

Hispanoamerican narrative reflection cannot be restricted only to the XIX century, since colonial period studies have evidenced Chronicles, Relations and different tales, from the second half of the XVI century, not only written by europeans or mixed-race people but also texts written by learned indigenous who added a radicalization of the denunciation and also a question to the domineering subject. This piece of work proposes a critical approach to a group of texts that, back then at the colonial period, denounced crimes narratively through different forms of the statement, making up one of the constants of the critical thinking-literary. These narratives, along with expanding memory, assumed the justice of mentioning and exposed act from the other's place, the history or the stories that account for those deeds.

Keywords: Latin-American critical thinking-literary, Colonial Studies, Hispanamerican Catholic Enlightenment, Natural History, Narrative Studies.

Recibido: 12/12/2016

Aceptado: 22/03/2017

Este trabajo se vincula al Proyecto DICYT 031751HL. Vicerrectoría de Investigación, Desarrollo e Innovación de la Universidad de Santiago de Chile. Igualmente amplía la base y reflexión del prólogo: "Memorias del crimen" del ensayo Poéticas del relato criminal. La violencia en la novela chilena de la dictadura (1973-1989) de Carlos Hernández Tello. Santiago de Chile, Ediciones Oxímoron, 2014.

** Chileno. Doctor en Literatura. Universidad de Santiago de Chile. Santiago, Chile. luis.hachim@ usach.cl 
En estas ovejas mansas y de las calidades susodichas por su hazedor e criador assi dotadas, entraron los españoles desde luego que las conocieron como lobos e tigres y leones crudelíssimos de muchos días hambrientos.

(Fray Bartolomé de las Casas, 1552).

\section{Antecedentes}

Si "la historia de la escritura es coincidente con la inauguración y desarrollo de la explotación" (55) como piensa Spivak (2008), la narrativa, efecto de realidad certificado por la lengua en los textos coloniales, tiene que ser investigada a partir de los hechos enunciados o más bien narrados. Así, se planteará la reflexión desde la narración de la simple acción criminal o el "hecho criminal". La posibilidad de una "narrativa criminal" no se constituye solo como tema o experiencia, sino más bien como problema narrativo. El crimen en las narraciones de Indias, Nuevo Mundo, desde el momento de instalación del sistema Colonial, se constituye como una escritura aparentemente factual (Genette 53) que se impone por su naturaleza significante. El pensamiento legal define la acción criminal como un "[...] enunciado que significa que la ley a esa acción la incluye en la clase de las acciones cuya ejecución se amenaza con pena" (Spolansky 3). En el Quiche, Anahuac, Tahuantinsuyu, la ley quedó suspendida y la violencia contra los indígenas tuvo representación textual en el corpus denominado discurso de la conquista. Las diferentes formas de narrar esos hechos establecen los siguientes niveles: 1. relatos de españoles sobre hechos de violencia entre españoles; 2. relatos de españoles sobre hechos de violencia contra los "indios"; 3. relatos de criollos (españoles americanos) sobre hechos de violencia entre criollos; 4. relatos de criollos sobre hechos de violencia contra "indios": 5. relatos de mestizos que narraron hechos de violencia entre los mestizos e indios; y 6. relatos de indígenas (letrados) que narraron hechos criminales, incluyendo a los sujetos y niveles anteriores. Tal vez la obra del Inca Garcilaso y la extensa carta de Guamán Poma sean ejemplos en este sentido.

En un artículo previo, "Esbozo de una narrativa del pensamiento crítico y literario en el periodo colonial”, se planteaba que a pesar de la masacre de tainos, nahuas, quiches, otomíes, quechuas, aimaras, mapuche, es decir el exterminio de los mal denominados "indios" [,] [a] más de quinientos años del establecimiento de Occidente, no 
se conoce reparación. El derecho suscribió la impunidad. Sin embargo, [...] no se trata de negar o afirmar Occidente, sino de actualizar una narrativa de sanidad en función de curar el trauma del “Descubrimiento", entonces el pensamiento reclama esa reparación. Las narrativas americanas junto con profundizar la memoria, asumieron la justicia, la justicia de nombrar y el acto narrativo que registró y relató la historia o las historias de esos crímenes. (Hachim Lara 22)

En las narrativas del periodo de Conquista y Colonia, existirían enunciados o registros sobre esos crímenes, evidentes en el caso de Fray Bartolomé de las Casas, o de Cristóbal de Molina (El almagrista o chileno), pero en crónicas, relaciones e historias predominan relatos ambiguos sobre esos hechos. Incluso, en ellas pareciera que las víctimas fueron los malhechores.

\section{Restos o vestigios}

Los vestigios o restos que incorpora el registro historiográfico en las narrativas del periodo colonial, acompañan la inclusión de América a Occidente. Asumo que postular una narrativa criminal en ese contexto en Chile es algo aventurado. Sin embargo, la reducción que la crítica ejerce, ignorando o tratando el hecho criminal como tema o patrocinando la descripción de tipos de personajes con el pretexto de la ficción, pareciera coartada. Así, se ha obviado la función autor, exacerbando la inmanencia e ignorando las poéticas que definen esos textos. Decidirse por la narrativa como eje apunta a cuestionar esas estrategias. Sabemos que los cronistas, historiadores, sacerdotes, soldados, en suma "autores" (tanto en el plano de la enunciación como en el plano del enunciado) de cartas, crónicas y relaciones, si bien escribieron desde la experiencia, optaron por una escritura en función de poéticas naturalistas, históricas o teológicas. Narrativamente mezclaron lo factual, enmascarando lo ficcional, sin embargo, el relato factual fue la forma privilegiada ${ }^{1}$. Siendo la raza uno de los ejes de dominación del con-

\footnotetext{
En un proyecto en desarrollo, titulado: La dinámica del relato factual y ficcional en las narrativas del periodo colonial y primera parte del siglo XIX, presentado por el Dr. Luis Hachim Lara y el Dr. (c) Pablo Hurtado Ruiz (Universidad de Santiago de Chile) proponen que, siendo la narrativa transversal a todo tipo de textos (desde el punto de vista de la forma de la expresión) en el periodo Colonial, la narrativa factual subordina la narrativa ficcional (o la enmascara) para atenuar la responsabilidad criminal. En cambio, en el periodo de la Colonialidad; siglo XIX en adelante, se invierte el orden, en tanto la narrativa ficcional enmascara o subordina las evidencias de la narrativa factual.
} 
quistador blanco, europeo y católico, la interacción problemática con el indígena fue incorporada en la trama legal y en los diferentes humanismos de la época. La mirada naturalista o "natural" en cartas, crónicas, relaciones, reconoce al "indio" o al "araucano", pero no al ser humano mapuche, taino, náhuatl, quiche, quechua. En el discurso de la Conquista, hasta el siglo XVII, no es fácil identificar agentes (hechores), ni procesos claros de la acción criminal, como evidencia. El responsable del empalamiento de Queupulican en Cañete el año 1558 en la narración de Mariño de Lobera, o en la historia de Jerónimo de Vivar, en Ercilla y Zúñiga o en la versión de Góngora Marmolejo, no es imposible de identificación. Considerando que el empalamiento constituye acción criminal no solo en la tradición cultural musulmana, sino también en la tradición europea, en versión rumana o española, podemos agregar el silencio histórico de cronistas y letrados españoles y criollos sobre la autoridad que inauguró esta técnica de tortura en Chile: es decir, García Hurtado de Mendoza y Manrique, IV marqués de Cañete y gobernador de Chile.

Igualmente, al revisar el significado escrito de lo criminal, podemos encontrarlo en la historia etimológica greco latina, pero principalmente en el Tesoro de la lengua castellana o española de Sebastián de Covarrubias, que especifica las acepciones que ayudarán a entenderlo, en el sentido que estas narrativas recuperan:

Crimen. El pecado grave, latine crimen, minis. Díjose del verbo griego [...] crino, iudico, porque debe ser juzgado, conviene a saber, castigado severamente; dice más que delicto. [ ] $\underline{\text { Crimen. }}$ laesae maiestatis, el que comete contra Dios o contra el rey; que delitos sean comprehendidos debajo deste nombre, consule iurisperitos. Criminal, lo que pertenece al crimen, como causa criminal, juez de causas criminales. Acusar a uno criminalmente. Escribano del crimen. Acriminar un negocio, exagerarle y encarecerle por malo. Criminoso, el que ha cometido muchos delitos. (De Covarrubias 630)

La relación crimen y pecado fue más propia del contexto de la Colonia que de la Colonialidad ${ }^{2}$, pero la analogía entre criminal y escribano

En el periodo Colonial hispanoamericano (siglo XVI al XVIII) se consolida el imperio o el proceso de hispanización a través de tres ejes de dominación: el eje de raza, el eurocentrismo y la implementación del capitalismo en su fase acerba. En la Colonialidad, después de los procesos de emancipación nacional, los españoles americanos o criollos administraron la herencia colonial perfeccionando el sistema de dominación (cf. Aníbal Quijano). 
en la acepción final es sorprendente. Leemos las peripecias de las víctimas condenadas por funcionarios de causas, es decir criminales -acepción referida a jueces, inquisidores o extirpadores de idolatríasque enjuiciaban, interrogaban, torturaban y/o mutilaban a miembros de castas (indígenas, mestizos, mulatos, coyotes, lobos, moriscos, zambaigos, salta atrás, etc.). En Covarrubias, la acepción criminal, resulta efectiva, puesto que la complicidad con la violencia perpetrada en América implicó a funcionarios de la corona.

\section{Complicidad autor/narrador}

En los textos coloniales la "aplicación imaginativa de la modalidad narrativa produce [...] buenos relatos, obras [...] interesantes, crónicas históricas creíbles (aunque no necesariamente 'verdaderas')" (Bruner 25). Los letrados europeos que ejecutaron el proyecto de la Corona y los criollos que incorporaron la alteridad y la diferencia en la administración del proyecto heredado, se inscribieron como Autores o sujetos de enunciación (A) en ese enunciado, coincidiendo a veces con el Narrador o sujeto de ese enunciado (N) y los Personajes (P) (Lejeune, 1994). La posibilidad de un nivel cinco y seis (el registro de enunciadores de las castas o de los propios letrados indígenas) es una acción entorpecida por imposición de la lengua, que acompaña al invasor y que predomina en los discursos sobre las Indias y/o el Nuevo Mundo.

Por otro lado, no se puede reducir la acción narrativa solo a la forma de la expresión o a la prosa. El recorrido histórico de Alonso de Ercilla se encuentra y desencuentra con la representación narrativa del riesgo que vive el sujeto de ese enunciado, en el enfrentamiento contra el araucano [en puridad mapuche]. En algunos de los textos revisados, se produce la coincidencia entre el (A) autor y el (N) narrador. El texto involucra a un lector (L) como referente histórico, que incorpora el enjuiciamiento de las acciones que exigió el proyecto. El lector activo también puede en gran medida inferir y en este acto recuperar o rectificar esas historias o narrativas que manifiestan sesgos del relato eurocéntrico. Por último, debemos asumir que este discurso es un componente más de una macro estructura discursiva, que en estos casos se clasifican como crónicas, historias, cartas o relaciones del "descubrimiento" y de la conquista.

El fundamento de lo propuesto debe partir del registro de evidencias (citas y registros documentales) más visibles en una genealogía arbitraria 
de una narrativa criminal. Se tratará de asumir espacios desprovistos de información en Chile e Hispanoamérica, en función de lograr una investigación que produzca conocimiento sobre estas áreas de estudio, mostrando que en las bases de la textualidad colonial hispanoamericana y chilena (del siglo XVI al XVIII) encontramos escrituras que se relacionan con narrativas de este tipo.

\section{Fundamentos}

A continuación, incluiré cronológicamente (evidencias) citas de documentos, fragmentos o textos parciales que refieren o narran acciones que caracterizaron o manifestaron sesgos de violencia y/o crimen:

\subsection{0 de abril de 1492:}

Provision de los Reyes mandando suspender el conocimiento de los negocios y cabsas criminales contra los que van con Cristóbal Colon, fasta que vuelvan.

E por la presente damos seguro á todas é cualesquier personas que fueren en las dichas carabelas con el dicho Cristóbal Colon, en el dicho viage que hace por Nuestro mandado á la parte del dicho Mar Océano, como dicho es, para que non les sea fecho mal ni daño ni desaguisado alguno en sus personas ni bienes, ni en cosa alguna de la suyo por razon de ningun delito que hayan fecho ni cometido fasta el dia de la fecha desta Nuestra Carta, é durante el tiempo que fueren ó estovieren allá, con la venida á sus casas, é dos meses despues. Porque vos mandamos á todos é á cada uno de vos, en vuestros logares é juresdiciones, que non conozcais de ninguna cabsa criminal, tocante á las personas que fueren con el dicho Cristóbal Colon en las dichas tres carabelas, durante el tiempo susodicho; porque Nuestra merced é voluntad es, que todo ello esté asi suspendido. [...]. Dada en la nuestra Cibdad de Granada á treinta dias del mes de Abril, año del Nascimiento de nuestro Señor Jesucristo de mil é cuatrocientos é noventa é dos años. - YO EL REY. - YO LA REINA. - Yo Joan de Coloma, Secretario del Rey e de la Reina nuestros Señores, la fice escrebir por su mandado. (Está firmada) En las espaldas está sellada en papel con cera colorada, y tiene las notas siguientes: - Acordada en 
forma. - Rodericus Doctor. - (Está firmado). - Francisco de Madrid, Chanciller. — (está firmado)._Derechos nihil._(Está rubricado en folios) $)^{3}$. (s.p.)

\subsection{Requerimiento (1514):}

De parte del muy alto e muy poderoso y muy católico defensor de la Yglesia, siempre vencedor y nunca vencido, el gran rey don Hernando el quinto de las Españas, de las Dos Çiçilias, de Iherusalerm y delas yslas e Tierra Firme del Mar Oçeano, etc., domador de las gentes barbaras, y de la muy alta e muy poderosa señora la Reyna doña Juana... [sic] [...] reconozcáis a la Yglesia por señora y superiora del universo mundo, y al Sumo Pontífiçe, llamado Papa, en su nonbre, y al Rey y a la Reyna nuestros señores en su lugar, como a superiores e señores y reyes desas yslas y tierra firme, por virtud de la dicha donaçion, y consintáis y deys lugar que setos padres religiosos declaren y prediquen lo susodicho. [...] Sy no lo hizierdes, o en ello dilaçión maloçiosamente pusierdes, çertificos que con la ayuda de Dios yo entraré poderosamente contra vosotros y vos haré guerra por todas las partes y maneras que yo pudiere, y vos subjetaré al yugo y obediencia de la Yglesia y de sus altezas, y tomaré vuestras personas y de vuestras mugeres e hijos y los haré esclavos y como tales los venderé y disporné dellos como Su Alteza mandare, y vos tomaré vuestros bienes, y vos haré todos los males e daños que pudiere, como a vasallos que no obedecen... (Morales Padrón 338-340)

Incluso, la lectura de este Requerimiento se hacía a indios en fuga.

\section{Siglo XVI}

5.1. El padre Cristóbal de Molina, apodado El almagrista o El chileno que llegó a Chile en la expedición de Diego de Almagro en su Relación de muchas cosas acaecidas en el Perú (1535) narra desde una perspectiva crítica. Así se relaciona con narrativas de otros autores, cuyos relatos vuelve a contar:

Español hubo en este viaje que metió doce indios en una cadena, y se alababa que todos doce murieron en ella, y que cuando

Original en el Archivo del Sr. Duque de Veraguas. Registrada en el Sello de Corte de Simancas. 
ya el indio había expirado, por espantar a los otros, y por no desaherrojarlos, les cortaban la cabeza por no abrir el candado de la cadena; tenían por ordinaria costumbre si un triste indio cansaba o adolecía, de no dejarle de la mano hasta que muriese del todo... (De Molina 87)

Sabemos que por su afán [d]enunciador, este cura escribe: "por manera de lo que aquí tratare más se podrá decir destruición del Pirú que conquista ni poblazón” (De Molina 59), coincidiendo con Las Casas en la perspectiva desarrollada en Brevísima relación de la destrucción de Las Indias (1552).

5.2. En la Carta al emperador Carlos V, de Pedro de Valdivia (4 de septiembre de 1545), el enunciador narra lo siguiente: "Y tomados alguno destos indios y atormentados, dixeron que su cacique, que era el principal señor del valle de Canconcagua, que los del Adelantado llamaron Chili, tenía nueva dello de los caciques de Copayapo, y ellos de los de Atacama, [...]" (La cursiva es mía; Toribio Medina 17).

El autor de la carta, narrador y personaje es el mismo que ordena el tormento, pero el registro de su acción es confuso en el enunciado, pues el fin de su narración era ganar el beneplácito del Rey.

5.3. Igualmente ejemplar nos parece la Crónica y relación copiosa y verdadera de los reinos de Chile de Gerónimo de Bibar, redactada aproximadamente en el año 1558, específicamente el Capítulo CXXXVI que reproduce narrativamente un relato más o menos común en varios cronistas e historiadores que se refieren a Caupolicán:

Viniendo por el camino acertó a encontrar a una india que era muger del Teopolican y traía un niño de un año. Como ella no pensaba que venía preso el Teopolican y le vió, comenzó a decirle: “¡Cómo tú eres Teopolican el valiente que decías que no te había de parar cristiano, que no le habías de matar, y a ti alzaron por general de la tierra, que ansí te dejaste prender de los españoles, y parécete cual vas atado, y que tenga yo hijo de un hombre tan cobarde como tú!" Y lo arrojó de una cuesta abajo y murió el niño. Cierto me parece grande animo y esfuerzo de muger, y que la podíamos comparar aquella buena muger caraginesa que se metió con dos hijos en el fuego porque el marido se había entregado a los romanos. Llevado el Teopolican a la ciudad, fue empalado y ansí pereció este mal indio tan enemigo de los españoles. (La cursiva es mía; 207) 
5.4. Historia de todas las cosas que han acaecido en el Reino de Chile y de los que han gobernado de Alonso de Góngora Marmolejo (1575). Capítulo XXVI:

acaeció una cosa entonces, que por ser dina de memoria la escribo, para que entienda el que esto leyere y considere cuán valientes hombres son estos bárbaros y cuán bien defienden su tierra. Unos corredores le trajeron a Don García un indio, al cual mandó que le cortasen las manos por las muñecas; ansí castigado lo envió adonde los señores principales estaban, y que les dijese si le venían a servir les guardaría la paz, y si no lo querían hacer que a todos había de poner de aquella manera. (264)

En Góngora Marmolejo no encontré la narración del empalamiento de Caupolicán.

5.5. La Araucana (1569, 1578 y 1589) de Alonso de Ercilla: Canto XXII. [Descripción en Segunda parte] "Entran los españoles en el estado de Arauco; traban los araucanos con ellos una reñida batalla; hace Rengo de su persona gran prueba; cortan las manos por justicia a Galuarino [sic], indio valeroso" (La cursiva es mía; 609). Luego, el canto XXXIV [Tercera parte]: “Hecha la confesión, como lo escribo, / con más rigor y priesa que advertencia, / luego a empalar y asaetearle vivo / fue condenado en pública sentencia" (902).

5.6. Crónica del Reino de Chile, reducida a nuevo método y estilo por el padre Bartolomé de Escobar, de la Compañía de Jesús (1594) de Pedro Mariño de Lobera. "Capítulo XV. De la batalla que hubo en la ciudad de Santiago entre los indios y españoles, donde mató doña Inés de Juárez [sic] siete caciques" y el capítulo LI de la tercera parte donde los "indios se comieron unos a otros".

5.7. Arauco domado (1596) de Pedro de Oña, quien asume la narración de la mutilación de Galvarino:

En cumplimiento pues de lo que digo,

le sentenciaron luego los hispanos

en que se le cortasen ambas manos,

para terror y ejemplo al enemigo;

porque, temiendo el áspero castigo,

dejase de seguir intentos vanos,

y a trueque de no vérselas cortadas

las manos a la paz viniese atadas. (La cursiva es mía; 116) 


\section{Siglo XVII}

6.1. Desengaño y reparo de las guerras de Chile (1614) de Alonso González de Nájera. Capítulo III Rel. VI: "Exquisitas y crueles muertes ejecutadas por los indios en algunos españoles” (57).

6.2. Histórica relación del Reino de Chile (1646) del jesuita Alonso de Ovalle. “Capítulo XXIII Conversión y muerte de Caupolicán”. La conversión ocurre antes del empalamiento:

Raya el sol de justicia en su entendimiento, y despidiendo la tenebrosa noche de la infidelidad, y derritiendo el hielo frío de su obstinación, le resuelve en ternuras y amorosos afectos, con que comienza a pedir con grandes ansias el bautismo. Acuden luego los sacerdotes; catequizanlo y instrúyenlo en las cosas necesarias de nuestra fe, según el tiempo dio lugar, y hallándole suficientemente dispuesto con el arrepentimiento de sus pecados y conversión a su Criador, tan tarde conocido y tan felizmente hallado, recibió la santa ablución y el carácter de cristiano, y tras él, la ejecución de la sentencia [...]. (La cursiva es mía; 308-309)

\section{Siglo XVIII}

7.1. Cesare Beccaria en su tratado De los delitos y de las penas (1764) planteaba: "Esta inútil prodigalidad de suplicios, que nunca ha conseguido hacer mejores a los hombres, me ha obligado a examinar si es la muerte verdaderamente útil y justa en un gobierno bien organizado. ¿Qué derecho pueden atribuirse éstos para despedazar a su semejantes?" (74). Los indígenas no eran semejantes a pesar de la bula Sublimis Dei de 1537 que declaró finalmente que los indios tenían alma.

7.2. Compendio de la Historia geográfica, natural y civil del Reino de Chile del jesuita Juan Ignacio Molina, publicado en Italia en el año 1776. El cura identifica a Alonso de Reynoso, Comandante de Cañete -"cuyo nombre se ha hecho detestable"- subalterno de García Hurtado de Mendoza y a quien jerárquicamente correspondió dar la orden de empalamiento de Caupolicán:

fue conducido [...], a un tabloado elevado, donde habiendo visto el instrumento del suplicio que no comprehende al principio y un negro destinado para excutarlo, queda tan irritado, que de un furioso puntapie echó abajo del tablado al verdugo, diciendo en alta voz: no hay espada, y otra mano mas digna de 
hacer morir un hombre de mi carácter. Esta no es justicia, es vil venganza. Pero tomado por fuerza, y hecho sentar en el agudo palo, espiró atravesado de muchas saetas. (191-192)

\section{Conclusión}

El estudio del crimen como problema narrativo en estos textos abre diversas alternativas y dilemas para la investigación literaria. En sus relatos los soldados, sacerdotes y funcionarios no escatimaron usos y abusos de retóricas, "mentirosas historias", fábulas, mitos y ficciones desde lo factual. La idea de entender la narrativa factual y ficcional (discurso factual y ficcional en Genette) como ejes, proponiendo que en el periodo Colonial la narrativa factual subordina la narrativa ficcional (o la enmascara) para atenuar la responsabilidad criminal. En cambio, en el periodo de la Colonialidad, del siglo XIX en adelante, se invierte el orden, en tanto, la narrativa ficcional enmascara o subordina las evidencias de la narrativa factual para asignar un valor fantástico a hechos reales, como el primer genocidio (de indios) de la época moderna, que implica consecuencias que se vinculan con los estudios de la cultura y además con el tratamiento real de los Humanismos en los espacios americanos. Igualmente, hemos leído el tratamiento que asumen algunos especialistas sobre la violencia en Europa y en Chile, desde la historiografía y el Derecho, pero "la gran mayoría de los documentos corresponde al siglo XVIII, con lo cual se pierde el rastro de los siglos anteriores, cuando los tribunales y el proceso penal eran aún más precarios" (Arancibia et al. 10). Además, se estudian desde la perspectiva administrativa y política del poder. Entonces, corresponde aclarar que en este trabajo se propone que la perspectiva narrativa interactúa provechosamente con los registros historiográficos, sin embargo, en primera instancia el problema se plantea en función de: a) la consideración de narrativas anteriores al siglo XVII. b) la incorporación de narrativas que no representan solo la Institucionalidad colonial o a los Victimarios como: Provisión de los Reyes (1492). Requerimiento (1514). Pedro de Valdivia (1545). Jerónimo de Vivar (1558). Góngora Marmolejo (1575). Mariño de Lobera (1594). Alonso de Ovalle (1646) y otros, sino también a sujetos Denunciantes: Cristóbal de Molina (El Almagrista 1535). Bartolomé de Las Casas (1552). Alonso de Ercilla (1569). Cesare Beccaria (1764). El Abate Juan Ignacio Molina (1776) y también letrados mestizos de ascendencia indígena, como el Inca Garcilaso, Guamán Poma de Ayala 
y otros. Por último, esta propuesta sobre la narrativa del crimen se vinculó a alguna de las postulaciones de nuevos investigadores chilenos, sin embargo estos reconocen que se han reducido al examen de textos a partir del siglo XVIII.

Finalmente y como se ha repetido, en la transición al siglo XIX el hecho criminal fue cooptado por la ficción. El desarrollo de una narrativa en ese contexto se dio en un marco normalizado y en función de la legalidad. Pero aun hoy, en la mayoría de los casos, la narrativa del cordero ha sido contada por los lobos.

\section{Referencias bibliográficas}

Arancibia, Claudia, José Tomás Cornejo y Carolina González. Pena de muerte en Chile colonial. Cinco casos de homicidio de la Real Audiencia: Santiago, Centro de Investigaciones Diego Barros Arana, RIL Editores, 2003.

Beccaria, Cesare. De los delitos y de las penas. Buenos Aires. Alianza, [1764] 1994.

Bruner, Jerome. Realidad mental y mundos posibles. Barcelona, Gedisa, 2006.

De Bibar, Gerónimo. Crónica y relación copiosa y verdadera de los Reynos de Chile. Transcripción paleográfica de Irving A. Leonard. Santiago, Fondo Histórico y Bibliográfico José Toribio Medina, 1966.

De Covarrubias, Sebastián. Tesoro de la lengua castellana o española. Luis Sánchez, Impresor del Rey N. S. 1611: Sub Voquem. Madrid, Vervuert, 2006.

De Ercilla y Zúñiga, Alonso. La Araucana. Edición de Isaías Lerner. Madrid, Cátedra, 2011.

De Góngora Marmolejo, Alonso. Historia de todas las cosas que han acaecido en el reino de Chile y de los que lo han gobernado. Estudio, edición y notas de Miguel Donoso R. Madrid, Iberoamericana, 2010.

De Molina, Cristóbal. Relación de muchas cosas acaecidas en el Perú. Crónicas peruanas de interés indígena. Ed. Francisco Esteve Barba. Madrid, Atlas, 1968.

De Oña, Pedro. Arauco domado. Santiago de Chile, Universitaria, 1979. 
De Ovalle, Alonso. Histórica relación del Reino de Chile. Santiago de Chile, Pehuén, 2003.

Genette, Gérard. Ficción y dicción. Barcelona, Lumen, 1993.

González de Nájera, Alonso. Desengaño y reparo de las guerras de Chile. Santiago de Chile, Editorial Ercilla, [1614] 1889.

Hachim Lara, Luis. "Esbozo de una narrativa del pensamiento crítico y literario en el periodo colonial”. Discursos/Prácticas, no. 3, 2010, pp. 13-23.

Lejeune, Philippe. El pacto autobiográfico y otros estudios. Madrid, Megazul-Endymion, 1994, pp. 49-75.

Mariño de Lobera, Pedro. Crónica del Reino de Chile, reducida a nuevo método y estilo por el padre Bartolomé de Escobar, de la Compañia de Jesús. Tomo VI Colección Historiadores de Chile. Santiago, Imprenta del Ferrocarril, [1594] 1865.

Medina, José Toribio. Cartas de Pedro de Valdivia que tratan el descubrimiento y conquista de Chile. Edición facsimilar dispuesta y anotada. Santiago de Chile, Fondo histórico y bibliográfico José Toribio Medina, MCMLIII.

Molina, Juan Ignacio. Compendio de la Historia civil del Reyno de Chile. Madrid, Imprenta de Sancha, 1795.

Morales Padrón, Francisco. “El Requerimiento”. Teoría y leyes de la Conquista. Madrid, Cultura Hispánica, 1979.

Quijano, Aníbal: “Colonialidad del poder, eurocentrismo y América Latina". La colonialidad del saber: eurocentrismo y ciencias sociales. Perspectivas latinoamericanas. Compilado por Edgardo Lander. Buenos Aires, CLACSO, 2000, pp. 201-246.

Spivak, Gayatry. "Estudios de la subalternidad”. Estudios postcoloniales. Comp. Sandro Mezzadra Sandro. Madrid, Traficantes de Sueños, 2008.

Spolansky, Norberto Eduardo. "El hecho criminal y los destinatarios de la ley". Cuadernos del departamento de Derecho Penal y Criminología. Universidad Nacional de Córdoba, no. 1, 1995, pp. 3-11. 